\title{
Existence of Solutions of Nonlinear Mixed Two-Point Boundary Value Problems for Third-Order Nonlinear Differential Equation
}

\author{
Yongxin Gao and Fengqin Wang \\ College of Science, Civil Aviation University of China, Tianjin 300300, China \\ Correspondence should be addressed to Yongxin Gao, yongxingao@sina.com \\ Received 17 February 2012; Revised 18 June 2012; Accepted 2 July 2012 \\ Academic Editor: Mehmet Sezer
}

Copyright (C) 2012 Y. Gao and F. Wang. This is an open access article distributed under the Creative Commons Attribution License, which permits unrestricted use, distribution, and reproduction in any medium, provided the original work is properly cited.

The authors use the upper and lower solution method to study the existence of solutions of nonlinear mixed two-point boundary value problems for third-order nonlinear differential equation $y^{\prime \prime \prime}=f\left(x, y, y^{\prime}, y^{\prime \prime}\right), y^{\prime}(b)=h\left(y^{\prime}(a)\right), p\left(y(a), y(b), y^{\prime}(a), y^{\prime}(b)\right)=0, g(y(a)$, $\left.y(b), y^{\prime}(a), y^{\prime}(b), y^{\prime \prime}(a), y^{\prime \prime}(b)\right)=0$. Some new existence results are obtained by developing the upper and lower solution method. Some applications are also presented.

\section{Introduction}

It is well known that the upper and lower solution method is a powerful tool for proving existence results for boundary value problems. The upper and lower solution method has been used to deal with the multipoint boundary value problems for second-order ordinary differential equations [1-4] and for higher-order ordinary differential equations [5-11]. There are fewer results on nonlinear mixed two-point boundary value problems for higher-order equations in the literature of ordinary differential equations. For this reason, we consider the third-order nonlinear ordinary differential equation:

$$
y^{\prime \prime \prime}=f\left(x, y, y^{\prime}, y^{\prime \prime}\right)
$$

together with the nonlinear mixed two-point boundary conditions

$$
\begin{gathered}
y^{\prime}(b)=h\left(y^{\prime}(a)\right), \\
p\left(y(a), y(b), y^{\prime}(a), y^{\prime}(b)\right)=0, \\
g\left(y(a), y(b), y^{\prime}(a), y^{\prime}(b), y^{\prime \prime}(a), y^{\prime \prime}(b)\right)=0,
\end{gathered}
$$


where the functions $f, p$, and $g$ are continuous and monotonic, $h$ is a homeomorphic mapping.

We will develop the upper and lower solution method for the boundary value problem

$$
\begin{gathered}
y^{\prime \prime \prime}=f\left(x, y, y^{\prime}, y^{\prime \prime}\right), \\
y^{\prime}(b)=h\left(y^{\prime}(a)\right), \\
p\left(y(a), y(b), y^{\prime}(a), y^{\prime}(b)\right)=0, \\
g\left(y(a), y(b), y^{\prime}(a), y^{\prime}(b), y^{\prime \prime}(a), y^{\prime \prime}(b)\right)=0
\end{gathered}
$$

and establish some new existence results. Furthermore, some applications are also presented.

\section{Preliminaries}

In this section, we will give some preliminary considerations and some lemmas which are essential to our main results.

Definition 2.1. Suppose the functions $\alpha(x)$ and $\beta(x) \in C^{(3)}[a, b]$ satisfy

$$
\begin{gathered}
\alpha^{(3)}(x) \geq f\left(x, \alpha(x), \alpha^{\prime}(x), \alpha^{\prime \prime}(x)\right), \\
\beta^{(3)}(x) \leq f\left(x, \beta(x), \beta^{\prime}(x), \beta^{\prime \prime}(x)\right), \\
\alpha^{\prime}(x) \leq \beta^{\prime}(x), \quad x \in[a, b], \\
\alpha(a)<\beta(a), \quad \alpha^{\prime}(a)<\beta^{\prime}(a) .
\end{gathered}
$$

Then $\alpha(x)$ and $\beta(x)$ are, respectively, called the lower and upper solutions of the BVP (1.3).

Because of Definition 2.1, it is clear that $\alpha(x) \leq \beta(x), x \in[a, b]$. Let $D=[a, b] \times$ $[\alpha(x), \beta(x)] \times\left[\alpha^{\prime}(x), \beta^{\prime}(x)\right]$.

Definition 2.2. Let $C[D \times \mathbb{R}, \mathbb{R}]$ denote the class of continuous functions from $D \times \mathbb{R}$ into $\mathbb{R}$, and let $f\left(x, y, y^{\prime}, y^{\prime \prime}\right) \in C[D \times \mathbb{R}, \mathbb{R}]$ and $\alpha(x), \beta(x) \in C^{(3)}[a, b]$ be lower and upper solutions of BVP (1.3). Suppose that there is a function $W(s) \in C\left[\mathbb{R}_{+},(0,+\infty)\right]$ such that

$$
\left|f\left(x, y, y^{\prime}, y^{\prime \prime}\right)\right| \leq W\left(\left|y^{\prime \prime}\right|\right)
$$

for every $\left(x, y, y^{\prime}, y^{\prime \prime}\right) \in D \times \mathbb{R}$, where

$$
\int_{\lambda}^{\infty} \frac{s}{W(s)} d s>\max _{x \in[a, b]} \beta^{\prime}(x)-\min _{x \in[a, b]} \alpha^{\prime}(x),
$$


with

$$
\lambda(b-a)=\max \left\{\left|\alpha^{\prime}(a)-\beta^{\prime}(b)\right|,\left|\alpha^{\prime}(b)-\beta^{\prime}(a)\right|\right\} .
$$

Then we say that $f$ satisfies Nagumo's condition on the set $D$ relative to $\alpha(x), \beta(x)$.

We assume throughout this paper the following.

$\left(H_{1}\right)$ There are lower and upper solutions $\alpha(x)$ and $\beta(x)$ of BVP (1.3) as Definition 2.1.

$\left(H_{2}\right)$ Function $f\left(x, y, y^{\prime}, y^{\prime \prime}\right)$ satisfies Nagumo's condition on the set $D$ relative to $\alpha(x), \beta(x)$.

$\left(H_{3}\right)$ Function $f\left(x, y, y^{\prime}, y^{\prime \prime}\right) \in C\left[[a, b] \times \mathbb{R}^{3}, \mathbb{R}\right]$ is nonincreasing in $y$.

$\left(H_{4}\right) h:\left[\alpha^{\prime}(a), \beta^{\prime}(a)\right] \rightarrow\left[\alpha^{\prime}(b), \beta^{\prime}(b)\right]$ is a homeomorphism with

$$
h\left(\alpha^{\prime}(a)\right)=\alpha^{\prime}(b), \quad h\left(\beta^{\prime}(a)\right)=\beta^{\prime}(b) .
$$

$\left(H_{5}\right)$ Function $p(s, t, u, v)$ is continuous on $\mathbb{R}^{4}$ and nondecreasing in $t, u, v$ and satisfies

$$
\begin{aligned}
& p\left(\beta(a), \beta(b), \beta^{\prime}(a), \beta^{\prime}(b)\right) \leq 0, \\
& p\left(\alpha(a), \alpha(b), \alpha^{\prime}(a), \alpha^{\prime}(b)\right) \geq 0 .
\end{aligned}
$$

$\left(H_{6}\right)$ Function $g(x, y, z, p, q, r)$ is continuous on $\mathbb{R}^{6}$ and nondecreasing in $x, y, q$ and nonincreasing in $r$, and it satisfies

$$
\begin{aligned}
& g\left(\beta(a), \beta(b), \beta^{\prime}(a), \beta^{\prime}(b), \beta^{\prime \prime}(a), \beta^{\prime \prime}(b)\right) \leq 0 \\
& g\left(\alpha(a), \alpha(b), \alpha^{\prime}(a), \alpha^{\prime}(b), \alpha^{\prime \prime}(a), \alpha^{\prime \prime}(b)\right) \geq 0
\end{aligned}
$$

It is not difficult to obtain the following lemma.

Lemma 2.3. The boundary value problem

$$
\begin{gathered}
y^{\prime \prime \prime}=f\left(x, y, y^{\prime}, y^{\prime \prime}\right), \\
y(a)=0, \quad y^{\prime}(a)=0, \quad y^{\prime}(b)=0
\end{gathered}
$$

has a Green function

$$
G(x, s)= \begin{cases}\frac{(x-s)^{2}}{2}-\frac{(b-s)(a-x)^{2}}{2(b-a)}, & a \leq s \leq x \leq b \\ \frac{-(b-s)(a-x)^{2}}{2(b-a)}, & a \leq x \leq s \leq b\end{cases}
$$


with

$$
\begin{aligned}
& \int_{a}^{b}|G(x, s)| d t \leq \frac{(b-a)^{3}}{12} \\
& \int_{a}^{b}\left|G_{x}(x, s)\right| d t \leq \frac{(b-a)^{2}}{4}, \\
& \int_{a}^{b}\left|G_{x x}(x, s)\right| d t \leq b-a .
\end{aligned}
$$

It is easy to prove the following lemma similarly to [12, page 25, Theorem 1.4.1].

Lemma 2.4. Assume that $\left(H_{1}\right),\left(H_{2}\right)$ hold. Then for any solution $y$ of $y^{\prime \prime \prime}=f\left(x, y, y^{\prime}, y^{\prime \prime}\right)$ with $\alpha(x) \leq y(x) \leq \beta(x), \alpha^{\prime}(x) \leq y^{\prime}(x) \leq \beta^{\prime}(x)$ on $[a, b]$, there exists a constant $N>0$ depending only on $\alpha, \beta, W$, such that

$$
\left|y^{\prime \prime}(x)\right| \leq N, \quad x \in[a, b]
$$

and one calls $N$ is Nagumo's constant.

Lemma 2.5. Assume that $\left(H_{1}\right)-\left(H_{3}\right)$ hold. Then for any constant $A \in[\alpha(a), \beta(a)], B \in$ $\left[\alpha^{\prime}(a), \beta^{\prime}(a)\right], C \in\left[\alpha^{\prime}(b), \beta^{\prime}(b)\right]$, the boundary value problem

$$
\begin{gathered}
y^{\prime \prime \prime}=f\left(x, y, y^{\prime}, y^{\prime \prime}\right), \\
y(a)=A, \\
y^{\prime}(a)=B, \\
y^{\prime}(b)=C
\end{gathered}
$$

at least has a solution $y \in C^{(3)}[a, b]$, with

$$
\begin{array}{r}
\alpha(x) \leq y(x) \leq \beta(x), \\
\alpha^{\prime}(x) \leq y^{\prime}(x) \leq \beta^{\prime}(x)
\end{array}
$$

on $[a, b]$.

Proof. By Lemma 2.3, it is clear that BVP (2.12) is equivalent to integral equation

$$
y(x)=\int_{a}^{b} G(x, s) f\left(s, y(s), y^{\prime}(s), y^{\prime \prime}(s)\right) d s+W(x),
$$

where $W(x)$ is a polynomial satisfying $y^{\prime \prime \prime}=0, y(a)=A, y^{\prime}(a)=B, y^{\prime}(b)=C$. 
Journal of Applied Mathematics

Denote

$$
m=\max \left\{\max _{x \in[a, b]}\left|\alpha^{\prime \prime}(x)\right|, \max _{x \in[a, b]}\left|\beta^{\prime \prime}(x)\right|, N+1\right\}
$$

where $N$ is Nagumo's constant.

Assume

$$
\begin{gathered}
f_{m}\left(x, y, y^{\prime}, y^{\prime \prime}\right)= \begin{cases}f\left(x, y, y^{\prime}, m\right), & y^{\prime \prime}>m, \\
f\left(x, y, y^{\prime}, y^{\prime \prime}\right), & -m \leq y^{\prime \prime} \leq m, \\
f\left(x, y, y^{\prime},-m\right), & y^{\prime \prime}<-m,\end{cases} \\
G\left(x, y, y^{\prime}, y^{\prime \prime}\right)= \begin{cases}f_{m}\left(x, \beta(x), y^{\prime}, y^{\prime \prime}\right), & y>\beta(x), \\
f_{m}\left(x, y, y^{\prime}, y^{\prime \prime}\right), & \alpha(x) \leq y \leq \beta(x), \\
f_{m}\left(x, \alpha(x), y^{\prime}, y^{\prime \prime}\right), & y<\alpha(x),\end{cases} \\
F\left(x, y, y^{\prime}, y^{\prime \prime}\right)= \begin{cases}G\left(x, y, \beta^{\prime}(x), y^{\prime \prime}\right)+\frac{y^{\prime}-\beta^{\prime}(x)}{1+\left(y^{\prime}\right)^{2}} & y^{\prime}>\beta^{\prime}(x), \\
G\left(x, y, y^{\prime}, y^{\prime \prime}\right), & \alpha^{\prime}(x) \leq y^{\prime} \leq \beta^{\prime}(x), \\
G\left(x, y, \alpha^{\prime}(x), y^{\prime \prime}\right)-\frac{\alpha^{\prime}(x)-y^{\prime},}{1+\left(y^{\prime}\right)^{2}} & y^{\prime}<\alpha^{\prime}(x) .\end{cases}
\end{gathered}
$$

Then $F\left(x, y, y^{\prime}, y^{\prime \prime}\right)$ is bounded and continuous on $[a, b] \times \mathbb{R}^{3}$. Suppose $\left|F\left(x, y, y^{\prime}, y^{\prime \prime}\right)\right| \leq$ $M ;\left|W^{(i)}(x)\right| \leq K(i=0,1,2), x \in[a, b]$.

Now, define an operator $T$ on the set $E=C^{(2)}[[a, b], \mathbb{R}]$ by

$$
T y(x)=\int_{a}^{b} G(x, s) F\left(s, y(s), y^{\prime}(s), y^{\prime \prime}(s)\right) d s+W(x)
$$

If $y \in E$, the norm is defined by

$$
\|y\|=\max _{x \in[a, b]}\left[|y(x)|+\left|y^{\prime}(x)\right|+\left|y^{\prime \prime}(x)\right|\right]
$$

It is clear that

$$
\begin{aligned}
& |(T y)(x)| \leq \frac{(b-a)^{3}}{12} M+K \\
& \left|(T y)^{\prime}(x)\right| \leq \frac{(b-a)^{2}}{4} M+K \\
& \left|(T y)^{\prime \prime}(x)\right| \leq(b-a) M+K .
\end{aligned}
$$


This shows that $T$ maps the closed, bounded, and convex set

$$
B=\left\{y \mid y \in E,\|y\| \leq \frac{(b-a)^{3} M}{12}+\frac{(b-a)^{2} M}{4}+(b-a) M+3 K\right\}
$$

into itself. Also, $T$ is continuous and $(T y)^{\prime}$ is bounded. All of these considerations imply that $T$ is completely continuous by Ascoli's theorem. Schauder' fixed point theorem then yields the fixed point $y$ of $T$ on $B$. In other words, the following boundary value problem

$$
\begin{gathered}
y^{\prime \prime \prime}=F\left(x, y, y^{\prime}, y^{\prime \prime}\right), \\
y(a)=A, \\
y^{\prime}(a)=B, \\
y^{\prime}(b)=C
\end{gathered}
$$

has a solution $y \in C^{(3)}[a, b]$, and satisfying $\alpha^{\prime}(x) \leq y^{\prime}(x) \leq \beta^{\prime}(x)$ and $\alpha(a) \leq y(a) \leq \beta(a)$, we have $\alpha(x) \leq y(x) \leq \beta(x), x \in[a, b]$.

In the following we prove that

$$
\alpha^{\prime}(x) \leq y^{\prime}(x) \leq \beta^{\prime}(x), \quad x \in[a, b]
$$

In fact, if it is invalid, there is no harm in setting the right inequality to be not true (the case that the left inequality is not true can be proved in the same way). By the assumption, if $y^{\prime}(x)>\beta^{\prime}(x)$, for some $x \in[a, b]$, then there is a $x_{0} \in(a, b)$ such that

$$
\begin{gathered}
y^{\prime}\left(x_{0}\right)-\beta^{\prime}\left(x_{0}\right)=\max _{x \in(a, b)}\left[y^{\prime}(x)-\beta^{\prime}(x)\right]>0, \\
y^{\prime \prime}\left(x_{0}\right)=\beta^{\prime \prime}\left(x_{0}\right), \quad y^{\prime \prime \prime}\left(x_{0}\right) \leq \beta^{\prime \prime \prime}\left(x_{0}\right) .
\end{gathered}
$$

Now, let

$$
\omega\left(x_{0}\right)= \begin{cases}\beta\left(x_{0}\right), & y\left(x_{0}\right)>\beta\left(x_{0}\right) \\ y\left(x_{0}\right), & \alpha\left(x_{0}\right) \leq y\left(x_{0}\right) \leq \beta\left(x_{0}\right) \\ \alpha\left(x_{0}\right), & y\left(x_{0}\right)<\alpha\left(x_{0}\right)\end{cases}
$$

They imply that $\alpha\left(x_{0}\right) \leq \omega\left(x_{0}\right) \leq \beta\left(x_{0}\right)$ and

$$
G\left(x_{0}, y\left(x_{0}\right), \beta^{\prime}\left(x_{0}\right), \beta^{\prime \prime}\left(x_{0}\right)\right)=f_{m}\left(x_{0}, \omega\left(x_{0}\right), \beta^{\prime}\left(x_{0}\right), \beta^{\prime \prime}\left(x_{0}\right)\right) .
$$


We have

$$
\begin{aligned}
y^{\prime \prime \prime}\left(x_{0}\right) & -\beta^{\prime \prime \prime}\left(x_{0}\right) \\
\geq & F\left(x_{0}, y\left(x_{0}\right), y^{\prime}\left(x_{0}\right), y^{\prime \prime}\left(x_{0}\right)\right)-f\left(x_{0}, \beta\left(x_{0}\right), \beta^{\prime}\left(x_{0}\right), \beta^{\prime \prime}\left(x_{0}\right)\right) \\
= & F\left(x_{0}, y\left(x_{0}\right), y^{\prime}\left(x_{0}\right), \beta^{\prime \prime}\left(x_{0}\right)\right)-f\left(x_{0}, \beta\left(x_{0}\right), \beta^{\prime}\left(x_{0}\right), \beta^{\prime \prime}\left(x_{0}\right)\right) \\
= & G\left(x_{0}, y\left(x_{0}\right), \beta^{\prime}\left(x_{0}\right), \beta^{\prime \prime}\left(x_{0}\right)\right)-f\left(x_{0}, \beta\left(x_{0}\right), \beta^{\prime}\left(x_{0}\right), \beta^{\prime \prime}\left(x_{0}\right)\right)+\frac{y^{\prime}\left(x_{0}\right)-\beta^{\prime}\left(x_{0}\right)}{1+\left(y^{\prime}\left(x_{0}\right)\right)^{2}} \\
> & G\left(x_{0}, y\left(x_{0}\right), \beta^{\prime}\left(x_{0}\right), \beta^{\prime \prime}\left(x_{0}\right)\right)-f\left(x_{0}, \beta\left(x_{0}\right), \beta^{\prime}\left(x_{0}\right), \beta^{\prime \prime}\left(x_{0}\right)\right) \\
= & f m\left(x_{0}, \omega\left(x_{0}\right), \beta^{\prime}\left(x_{0}\right), \beta^{\prime \prime}\left(x_{0}\right)\right)-f\left(x_{0}, \beta\left(x_{0}\right), \beta^{\prime}\left(x_{0}\right), \beta^{\prime \prime}\left(x_{0}\right)\right) \\
= & f\left(x_{0}, \omega\left(x_{0}\right), \beta^{\prime}\left(x_{0}\right), \beta^{\prime \prime}\left(x_{0}\right)\right)-f\left(x_{0}, \beta\left(x_{0}\right), \beta^{\prime}\left(x_{0}\right), \beta^{\prime \prime}\left(x_{0}\right)\right) \\
\geq & 0
\end{aligned}
$$

which contradicts (2.24); hence, (2.22) is true.

Further, by the definition of $F, y$ is a solution of the boundary value problem

$$
\begin{gathered}
y^{\prime \prime \prime}=f_{m}\left(x, y, y^{\prime}, y^{\prime \prime}\right), \\
y(a)=A, \\
y^{\prime}(a)=B, \\
y^{\prime}(b)=C .
\end{gathered}
$$

Because there is a $\xi \in[a, b]$, such that

$$
\left|y^{\prime \prime}(\xi)\right|=\frac{\left|y^{\prime}(b)-y^{\prime}(a)\right|}{b-a} \leq \lambda<m,
$$

so $[a, b]$ has a maximal subinterval $[c, d]$ with interior point $\xi$, for any $x \in[c, d],\left|y^{\prime \prime}(x)\right| \leq m$. Hence, for $x \in[c, d], y(x)$ is the solution of BVP (2.12). And by Lemma 2.4, we have $\left|y^{\prime \prime}(x)\right| \leq$ $N<m$; this contracts that $[c, d]$ is the maximal subinterval, so we know $[c, d]=[a, b]$. Consequently, $y$ is a solution of BVP (2.12).

\section{Main Results}

Theorem 3.1. Assume $\left(H_{1}\right)-\left(H_{4}\right),\left(H_{6}\right)$ hold, then BVP

$$
\begin{gathered}
y^{\prime \prime \prime}=f\left(x, y, y^{\prime}, y^{\prime \prime}\right), \\
y(a)=A \\
y^{\prime}(b)=h\left(y^{\prime}(a)\right), \\
g\left(y(a), y(b), y^{\prime}(a), y^{\prime}(b), y^{\prime \prime}(a), y^{\prime \prime}(b)\right)=0
\end{gathered}
$$


has a solution $y \in C^{(3)}[a, b]$, satisfying

$$
\begin{array}{r}
\alpha(x) \leq y(x) \leq \beta(x), \\
\alpha^{\prime}(x) \leq y^{\prime}(x) \leq \beta^{\prime}(x)
\end{array}
$$

on $[a, b]$.

Proof. By Lemma 2.5, we know that the boundary value problem

$$
\begin{gathered}
y^{\prime \prime \prime}=f\left(x, y, y^{\prime}, y^{\prime \prime}\right), \\
y(a)=A, \\
y^{\prime}(a)=B, \\
y^{\prime}(b)=h(B)
\end{gathered}
$$

has a solution $y \in C^{(3)}[a, b]$, with

$$
\begin{array}{r}
\alpha(x) \leq y(x) \leq \beta(x), \\
\alpha^{\prime}(x) \leq y^{\prime}(x) \leq \beta^{\prime}(x)
\end{array}
$$

on $[a, b]$. For any $A \in[\alpha(a), \beta(a)], B \in\left[\alpha^{\prime}(a), \beta^{\prime}(a)\right]$.

For fixed $A$, if $B=\alpha^{\prime}(a)$, then $y^{\prime \prime}(a) \geq \alpha^{\prime \prime}(a), y^{\prime \prime}(b) \leq \alpha^{\prime \prime}(b)$. By $\left(H_{6}\right)$, we know

$$
g\left(y(a), y(b), y^{\prime}(a), y^{\prime}(b), y^{\prime \prime}(a), y^{\prime \prime}(b)\right) \geq g\left(\alpha(a), \alpha(b), \alpha^{\prime}(a), \alpha^{\prime}(b), \alpha^{\prime \prime}(a), \alpha^{\prime \prime}(b)\right) \geq 0
$$

On the other hand, if $B=\beta^{\prime}(a)$, then $y^{\prime \prime}(a) \leq \beta^{\prime \prime}(a), y^{\prime \prime}(b) \geq \beta^{\prime \prime}(b)$. By $\left(H_{6}\right)$, we have

$$
g\left(y(a), y(b), y^{\prime}(a), y^{\prime}(b), y^{\prime \prime}(a), y^{\prime \prime}(b)\right) \leq g\left(\beta(a), \beta(b), \beta^{\prime}(a), \beta^{\prime}(b), \beta^{\prime \prime}(a), \beta^{\prime \prime}(b)\right) \leq 0
$$

Define the following sets:

$$
\begin{aligned}
\Pi(y)= & \left\{y \mid y^{\prime \prime \prime}=f\left(x, y, y^{\prime}, y^{\prime \prime}\right),\right. \\
& \left.y(a)=A, y^{\prime}(a)=B, y^{\prime}(b)=h(B) ; A \in[\alpha(a), \beta(a)], B \in\left[\alpha^{\prime}(a), \beta^{\prime}(a)\right]\right\}, \\
M_{1}=\{ & B \mid B \in\left[\alpha^{\prime}(a), \beta^{\prime}(a)\right], y(x) \in \Pi(y), \\
& \left.g\left(y(a), y(b), y^{\prime}(a), y^{\prime}(b), y^{\prime \prime}(a), y^{\prime \prime}(b)\right)>0\right\}, \\
M_{2}=\{ & B \mid B \in\left[\alpha^{\prime}(a), \beta^{\prime}(a)\right], y(x) \in \Pi(y), \\
& \left.g\left(y(a), y(b), y^{\prime}(a), y^{\prime}(b), y^{\prime \prime}(a), y^{\prime \prime}(b)\right)<0\right\} .
\end{aligned}
$$


Obviously, $\Pi(y)$ is nonempty. If the theorem is not true, we know that $M_{1}$ and $M_{1}$ are all nonempty, and $M_{1} \cup M_{2}=\left[\alpha^{\prime}(a), \beta^{\prime}(a)\right]$. we claim that $M_{1}$ is closed. To see this, let $B_{n} \in M_{1}$, with $B_{n} \rightarrow B_{0}(n \rightarrow \infty)$. Consider the following boundary value problem:

$$
\begin{gathered}
y^{\prime \prime \prime}=f\left(x, y, y^{\prime}, y^{\prime \prime}\right), \\
y(a)=A, \\
y^{\prime}(a)=B_{n,} \\
y^{\prime}(b)=h\left(B_{n}\right) .
\end{gathered}
$$

By Lemma 2.5, it is known that, for every $n \in N$, BVP (3.8) has a solution $y_{n}(x) \in C^{(3)}[a, b]$, satisfying

$$
\alpha(x) \leq y_{n}(x) \leq \beta(x), \quad \alpha^{\prime}(x) \leq y_{n}^{\prime}(x) \leq \beta^{\prime}(x), \quad x \in[a, b]
$$

and, by Lemma 2.4, we know $\left|y_{n}^{\prime \prime}(x)\right| \leq N$.

Clearly, sequences $\left\{y_{n}(x)\right\},\left\{y_{n}^{\prime}(x)\right\},\left\{y_{n}^{\prime \prime}(x)\right\}$ are uniformly bounded and equicontinuous on $[a, b]$. Consequently, there exists a subsequence of $y_{n}(x)$ which converges uniformly on $[a, b]$, to a solution $y_{0}(x)$ of the BVP:

$$
\begin{gathered}
y^{\prime \prime \prime}=f\left(x, y, y^{\prime}, y^{\prime \prime}, y^{\prime \prime \prime}\right), \\
y(a)=A, \\
y^{\prime}(a)=B_{0}, \\
y^{\prime}(b)=h\left(B_{0}\right)
\end{gathered}
$$

with

$$
g\left(y_{0}(a), y_{0}(b), y_{0}^{\prime}(a), y_{0}^{\prime}(b), y_{0}^{\prime \prime}(a), y_{0}^{\prime \prime}(b)\right) \geq 0
$$

By assumption, equality cannot occur, so that

$$
g\left(y_{0}(a), y_{0}(b), y_{0}^{\prime}(a), y_{0}^{\prime}(b), y_{0}^{\prime \prime}(a), y_{0}^{\prime \prime}(b)\right)>0
$$

and thus $B_{0} \in M_{1}$. Consequently, $M_{1}$ is closed. Likewise, we may show $M_{2}$ is closed. This is a contradiction and proves the theorem.

Similar to the proof of Theorem 3.1, we can obtain the following theorem. 
Theorem 3.2. Assume $\left(H_{1}\right)-\left(H_{6}\right)$ hold, then $B V P$

$$
\begin{gathered}
y^{\prime \prime \prime}=f\left(x, y, y^{\prime}, y^{\prime \prime}\right), \\
y^{\prime}(b)=h\left(y^{\prime}(a)\right), \\
p\left(y(a), y(b), y^{\prime}(a), y^{\prime}(b)\right)=0, \\
g\left(y(a), y(b), y^{\prime}(a), y^{\prime}(b), y^{\prime \prime}(a), y^{\prime \prime}(b)\right)=0
\end{gathered}
$$

has a solution $y \in C^{(3)}[a, b]$, satisfying

$$
\begin{array}{r}
\alpha(x) \leq y(x) \leq \beta(x), \\
\alpha^{\prime}(x) \leq y^{\prime}(x) \leq \beta^{\prime}(x)
\end{array}
$$

on $[a, b]$.

\section{Applications}

We all know it is difficult to find a solution of some nonlinear ordinary differential equation. But according to Theorem 3.2, we can know whether a boundary value problem, especially a nonlinear boundary value problem, has a solution and we also can know the existence regions of the solution and its derivative.

Example 4.1. Consider the following linear boundary value problem

$$
\begin{gathered}
y^{\prime \prime \prime}(x)=-y(x)+2 y^{\prime \prime}(x), \quad x \in[0,1], \\
y^{\prime}(1)-2 e y^{\prime}(0)=0, \\
(-3 e-2) y(0)+y(1)+y^{\prime}(0)+y^{\prime}(1)=0, \\
y(0)+y(1)-4 y^{\prime}(0)-5 y^{\prime}(1)+y^{\prime \prime}(0)-y^{\prime \prime}(1)=0 .
\end{gathered}
$$

It is easy to know that $\alpha(x)=-x e^{x}-1, \beta(x)=x e^{x}+1$ are lower and upper solutions of the linear boundary value problem, respectively, where

$$
\begin{gathered}
h(s)=2 e s, \quad p(s, t, u, v)=(-3 e-2) s+t+u+v, \\
g(x, y, z, p, q, r)=x+y-4 z-5 p+q-r
\end{gathered}
$$


and all assumptions of Theorem 3.2 hold. So the linear boundary value problem has a solution $y(x)$ satisfying

$$
\begin{aligned}
& -x e^{x}-1 \leq y(x) \leq x e^{x}+1, \\
& -e^{x}-x e^{x} \leq y^{\prime}(x) \leq e^{x}+x e^{x} .
\end{aligned}
$$

Obviously, the trivial solution of the linear boundary value problem is one.

Example 4.2. Consider nonlinear boundary value problem

$$
\begin{gathered}
y^{\prime \prime \prime}(x)=-y(x)+\left[y^{\prime \prime}(x)\right]^{2}-y^{\prime \prime}(x), \quad x \in\left[\frac{\pi}{4}, \frac{\pi}{2}\right], \\
y^{\prime}\left(\frac{\pi}{2}\right)-\sin \left(\sqrt{2} \pi y^{\prime}\left(\frac{\pi}{4}\right)\right)=0 \\
y^{2}\left(\frac{\pi}{4}\right)+\frac{1}{4} y\left(\frac{\pi}{2}\right)+\frac{1}{8} y^{\prime}\left(\frac{\pi}{4}\right)+y^{\prime}\left(\frac{\pi}{2}\right)=0 \\
y\left(\frac{\pi}{4}\right)+\frac{1}{8} y\left(\frac{\pi}{2}\right)+\left(y^{\prime}\left(\frac{\pi}{4}\right)\right)^{2}+\left(y^{\prime}\left(\frac{\pi}{2}\right)\right)^{2}+y^{\prime \prime}\left(\frac{\pi}{4}\right)-\frac{1}{8} y^{\prime \prime}\left(\frac{\pi}{2}\right)=0 .
\end{gathered}
$$

It is easy to verify that $\alpha(x)=-\sin (x), \beta(x)=0$ are lower and upper solutions of the nonlinear boundary value problem, respectively, where

$$
\begin{gathered}
h(s)=\sin (\sqrt{2} \pi s), \quad p(s, t, u, v)=s^{2}+\frac{1}{4} t+\frac{1}{8} u+v, \\
g(x, y, z, p, q, r)=x+\frac{1}{8} y+z^{2}+p^{2}+q-\frac{1}{8} r
\end{gathered}
$$

and all assumptions of Theorem 3.2 hold, so the BVP has a solution $y(x)$ satisfying

$$
-\sin (x) \leq y(x) \leq 0, \quad-\cos (x) \leq y^{\prime}(x) \leq 0
$$

\section{Conclusion}

In this paper, we study a nonlinear mixed two-point boundary value problem for a thirdorder nonlinear ordinary differential equation. Some new existence results are obtained by developing the upper and lower solution method. Furthermore, some applications are also presented.

\section{Acknowledgments}

The work is supported by the Fundamental Research Funds for the Central Universities (no. ZXH2012 K004) and Civil Aviation University of China Research Funds (no. 2012KYM05). The authors would like to thank the referees for their valuable comments. 


\section{References}

[1] L. H. Erbe, "Existence of solutions to boundary value problems for second order differential equations," Nonlinear Analysis, vol. 6, no. 11, pp. 1155-1162, 1982.

[2] S. Leela, "Monotone method for second order periodic boundary value problems," Nonlinear Analysis, vol. 7, no. 4, pp. 349-355, 1983.

[3] Z. Zhang and J. Wang, "The upper and lower solution method for a class of singular nonlinear second order three-point boundary value problems," Journal of Computational and Applied Mathematics, vol. 147, no. 1, pp. 41-52, 2002.

[4] I. Rachunková, "Upper and lower solutions and topological degree," Journal of Mathematical Analysis and Applications, vol. 234, no. 1, pp. 311-327, 1999.

[5] Q. Zhang, S. Chen, and J. Lü, "Upper and lower solution method for fourth-order four-point boundary value problems," Journal of Computational and Applied Mathematics, vol. 196, no. 2, pp. 387393, 2006.

[6] J. Ehme, P. W. Eloe, and J. Henderson, "Upper and lower solution methods for fully nonlinear boundary value problems," Journal of Differential Equations, vol. 180, no. 1, pp. 51-64, 2002.

[7] A. Cabada, "The method of lower and upper solutions for second, third, fourth, and higher order boundary value problems," Journal of Mathematical Analysis and Applications, vol. 185, no. 2, pp. 302 320, 1994 .

[8] G. A. Klaasen, "Differential inequalities and existence theorems for second and third order boundary value problems," Journal of Differential Equations, vol. 10, pp. 529-537, 1971.

[9] Q. Yao and Y. Feng, "The existence of solution for a third-order two-point boundary value problem," Applied Mathematics Letters, vol. 15, no. 2, pp. 227-232, 2002.

[10] M. Ruyun, Z. Jihui, and F. Shengmao, "The method of lower and upper solutions for fourth-order two-point boundary value problems," Journal of Mathematical Analysis and Applications, vol. 215, no. 2, pp. 415-422, 1997.

[11] Y. X. Gao, "Existence of solutions of three-point boundary value problems for nonlinear fourth order differential equation," Applied Mathematics and Mechanics, vol. 17, no. 6, pp. 543-550, 1996.

[12] S. R. Bernfeld and V. Lakshmikantham, An Introduction to Nonlinear Boundary Value Problems, Academic Press, New York, NY, USA, 1974. 


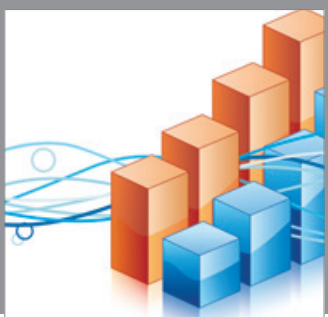

Advances in

Operations Research

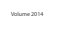

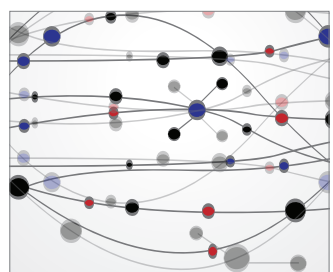

\section{The Scientific} World Journal
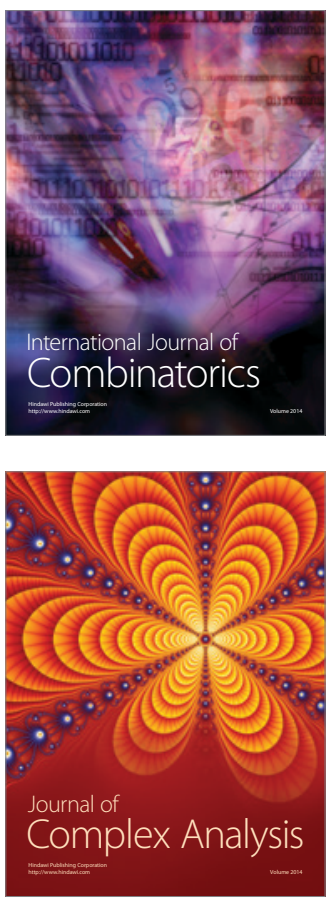

International Journal of

Mathematics and

Mathematical

Sciences
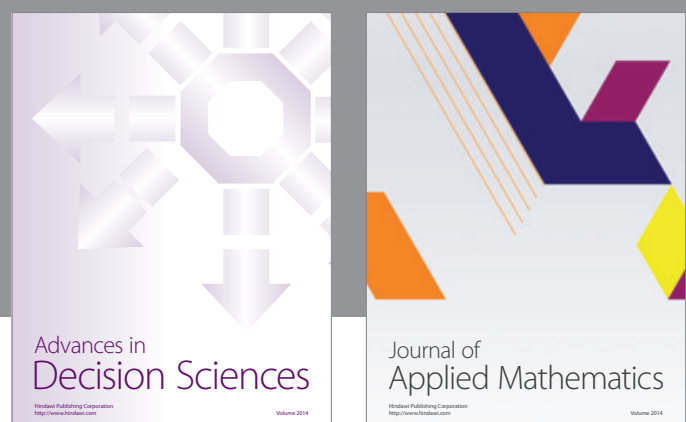

Journal of

Applied Mathematics
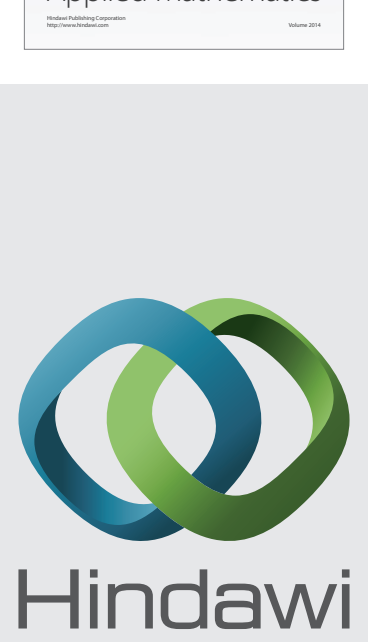

Submit your manuscripts at http://www.hindawi.com
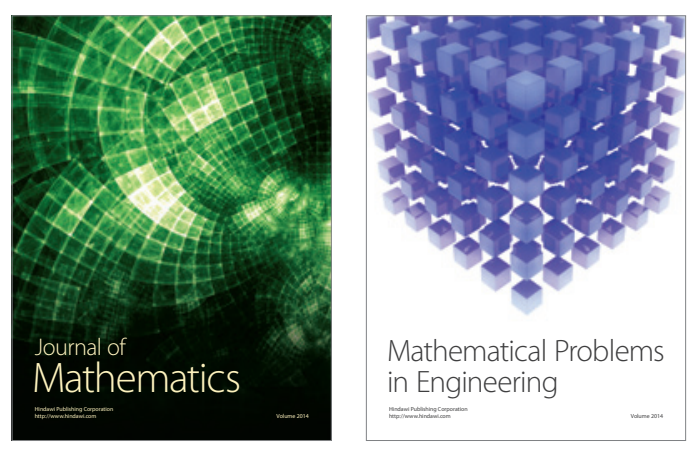

Mathematical Problems in Engineering
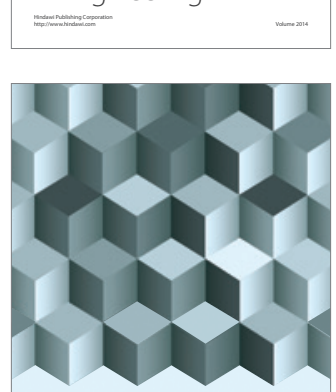

Journal of

Function Spaces
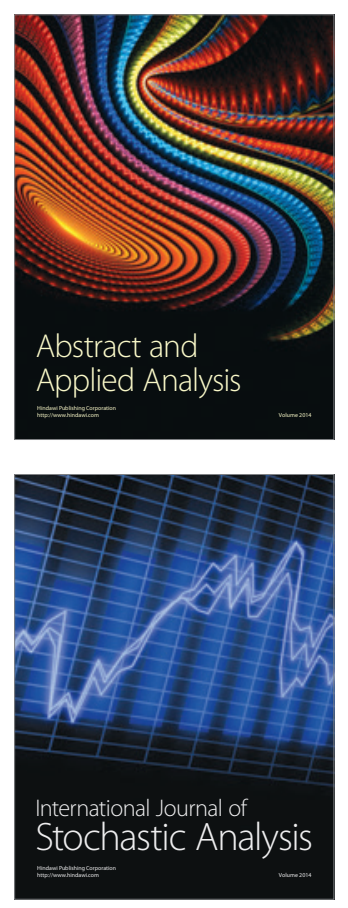

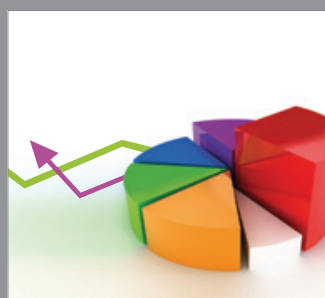

ournal of

Probability and Statistics

Promensencen
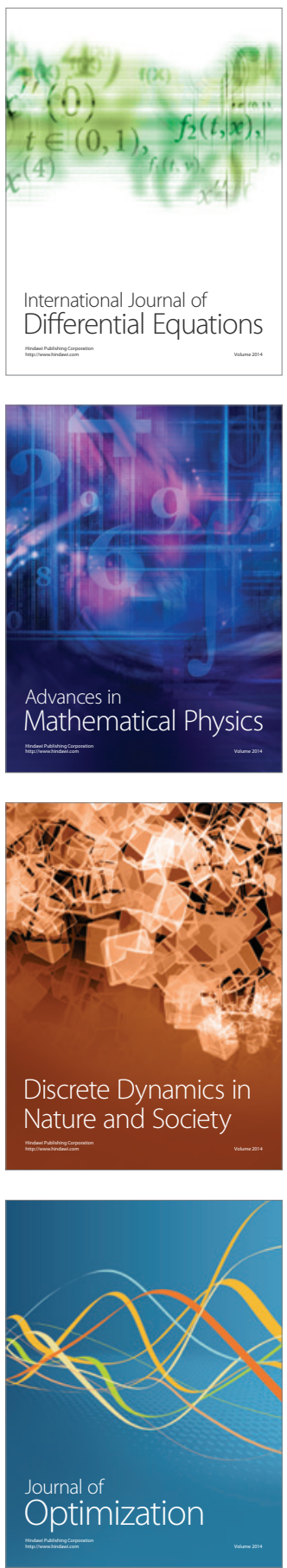